\title{
Clinical Evaluation of a Polyacid-modified Resin Composite in Class V Carious Lesions: 3-Year Results
}

\author{
Mustafa DEMIRCI ${ }^{1}$, Handan ERSEV ${ }^{2}$, Mert TOPCUBASI ${ }^{1}$ and Mete ÜÇOK ${ }^{1}$ \\ ${ }^{\mathrm{l}}$ Department of Conservative Dentistry, Istanbul University, Faculty of Dentistry, Capa, 34390 Istanbul, Turkey \\ ${ }^{2}$ Department of Endodontics, Ístanbul University, Faculty of Dentistry, Capa, 34390 Istanbul, Turkey \\ Corresponding author, E-mail:demirci.md@superonline.com
}

Received April 11, 2005/Accepted June 7, 2005

This study evaluated the three-year clinical performance of Class $\mathrm{V}$ restorations made of a polyacid-modified resin composite, Dyract. Ninety-two Class V carious lesions in 28 patients were restored with Dyract. Restorations were clinically evaluated at baseline, first, second, and third year recall visits, according to the modified Ryge criteria by two experienced, calibrated examiners. Retention rate after three years in Class V carious restorations was $92.4 \%$, with only seven failed restorations. Color change and marginal discoloration in restorations were found to be statistically significant $(p=0.013$ and $p<0.001$, respectively) at the end of third year, but none of the affected restorations required replacement. The results of this study revealed that at the end of three years, Dyract exhibited good clinical success rate but significant color change and marginal discoloration in Class $\mathrm{V}$ carious lesions.

Key words : Polyacid-modified resin composite, Clinical evaluation, Carious lesions

\section{INTRODUCTION}

Studies and clinical observations on traditional glass ionomer cements have shown that the material exhibits a number of advantages such as chemical bonding to enamel and dentin and fluoride release ${ }^{1,2)}$. On the other hand, disadvantages of the material include sensitivity to humidity and dehydration, low resistance to wear and fatigue, and a short setting time ${ }^{1)}$. To overcome these shortcomings and to impart the advantageous properties of the composites to the material, the liquid part of the material was modified so that hybrid materials were developed ${ }^{3-5)}$. These developments were achieved by using polymerizable monomer/prepolymer or polymerizable polyalkenoic acid instead of polyalkenoic acid, and polymerizable monomer/prepolymer in addition to polyalkenoic acid $^{3)}$. Alternatively, acid monomers were used instead of polyalkenoic acid. Acid monomers are acidic in character and have active groups that can polymerize ${ }^{3)}$. Chemically, hybrid materials are between glass ionomer cements and composite resins ${ }^{6)}$. As such, they are divided into two groups: resin-modified glass ionomers and polyacid-modified resin composites (compomers). Resin-modified glass ionomer cements are more like conventional glass ionomer cements while compomers are similar to composite resins ${ }^{3,4,7,8)}$.

One example in the polyacid-modified resin composite group is Dyract ${ }^{3)}$, which is a single component material. The liquid part of the single component paste has an acid monomer, TCB (diester of 2hydroxyethyl methacrylate and butan tetracarboxylic acid). This acid monomer is a product of the reaction between butane tetracarboxylic acid and 2hydroxyethyl methacrylate ${ }^{3,9)}$. This material contains two acidic carboxylate groups $(\mathrm{COOH})$ and two polymerizable methacrylate groups within the same molecule. The filler is a reactive silicate glass $(72 \%)$ containing fluoride. The material cures by crosslinking where the free radical polymerization of the additional co-monomers and monomers of the liquid (UDMA) (urethane dimethacrylate) is initiated by light exposure ${ }^{3)}$. Following the light-curing phase, an acid-base reaction occurs only after the restoration is placed and water is absorbed from saliva. In the presence of water from the tooth and oral environment, the active carboxylate group of TCB, which is now part of the polymerized material, can react with glass to initiate an acid-base reaction ${ }^{3,7,10,11)}$, leading to inadequate material setting ${ }^{7}$.

Dyract's bonding to tooth structure is achieved using a PSA Prime/Adhesive ${ }^{11)}$. One of the components of PSA Prime/Adhesive is PENTA (dipentaerythritol penta-acrylate phosphoric acid ester $)^{9,11,12)}$. It is suggested that the hydrophilic phospate groups in the PENTA molecule react with the tooth surface and form an ionic bond with the calcium ions of hydroxyapatite $\mathrm{e}^{9,11,13-16)}$.

Although Dyract releases less fluoride when compared with traditional glass ionomer cements ${ }^{17-20)}$, it has gained great clinical use because of its ease of application, low dissolution ${ }^{10,21,22)}$, composite-like esthetics, and photopolymerizability (command cure) ${ }^{10)}$. Moreover, clinical studies on Dyract have shown that it is effective in restoring cervical lesions ${ }^{1123-28)}$.

This study evaluated the clinical performance of a polyacid-modified resin composite, Dyract (DeTrey/ 
Dentsply), in Class $\mathrm{V}$ carious cavities at baseline, first, second, and third year recall visits in regard to color match, marginal discoloration, wear or loss of anatomical form, caries, marginal adaptation, and surface texture.

\section{MATERIALS AND METHODS}

This study was performed at the Department of Conservative Dentistry, Istanbul University. Ninety-two Class V carious lesions in 28 patients were selected. The average age of the patients was 34.8 years

Table 1 Direct Clinical Evaluation Criteria (Modified Ryge Criteria)

\begin{tabular}{|c|c|c|}
\hline Rating & Aspect & Method \\
\hline \multicolumn{3}{|c|}{ Color match } \\
\hline Alfa (A) & $\begin{array}{l}\text { There is no mismatch in color, shade and/or translucency between the restoration and the } \\
\text { adjacent tooth structure. }\end{array}$ & $\begin{array}{l}\text { Visual } \\
\text { inspection }\end{array}$ \\
\hline Bravo (B) & $\begin{array}{l}\text { There is a mismatch in color, shade and/or translucency between the restoration and the } \\
\text { adjacent tooth structure, but the mismatch is within the normal range of tooth color, } \\
\text { shade and/or translucency. }\end{array}$ & $\begin{array}{l}\text { Visual } \\
\text { inspection }\end{array}$ \\
\hline Charlie (C) & $\begin{array}{l}\text { The mismatch is between restoration and adjacent tooth structure outside the normal range } \\
\text { of tooth color, shade and/or translucency. }\end{array}$ & $\begin{array}{l}\text { Visual } \\
\text { inspection }\end{array}$ \\
\hline \multicolumn{3}{|c|}{ Cavosurface marginal discoloration } \\
\hline Alfa (A) & $\begin{array}{l}\text { There is no discoloration anywhere on the margin between the restoration and the tooth } \\
\text { structure. }\end{array}$ & $\begin{array}{l}\text { Visual } \\
\text { inspection }\end{array}$ \\
\hline Bravo (B) & $\begin{array}{l}\text { There is discoloration anywhere on the margin between the restoration and the tooth } \\
\text { structure, but the discoloration has not penetrated along the margin of the restorative ma- } \\
\text { terial in a pulpal direction and can be polished away. }\end{array}$ & $\begin{array}{l}\text { Visual } \\
\text { inspection }\end{array}$ \\
\hline Charlie (C) & $\begin{array}{l}\text { The discoloration has penetrated along the margin of the restorative material in a pulpal } \\
\text { direction. }\end{array}$ & $\begin{array}{l}\text { Visual } \\
\text { inspection }\end{array}$ \\
\hline
\end{tabular}

\section{Wear/Anatomic form}

Alfa (A) The restoration is not under-contoured, that is, the restorative material is not discontinuous with existing anatomic form.

Bravo (B) The restoration is under-contoured, that is, the restorative material is discontinuous with existing anatomic form, but sufficient restorative material is not missing so as to expose the dentin or base.

Charlie (C) Sufficient restorative material is missing so as to expose the dentin or base.

Visual inspection and explorer

Visual inspection and explorer Visual inspection

\section{Caries}

Alfa (A) There is no evidence of caries contiguous with the margin of the restoration.

Visual inspection Visual

Bravo (B) There is evidence of caries contiguous with the margin of the restoration. inspection

\section{Marginal adaptation}

Alfa (A) There is no visible evidence of a crevice along the margin into which the explorer will penetrate.

Visual inspection and explorer

Bravo (B) There is visible evidence of a crevice along the margin into which the explorer will penetrate. The dentin or base is not exposed.

Visual inspection and explorer

Charlie (C) There is visible evidence of a crevice along the margin into which the explorer will penetrate. The dentin or base is exposed.

Delta (D) The restoration is fractured or missing in part or in toto.

Visual inspection and explorer Visual inspection and explorer

Surface texture

Alfa (A) Surface of restoration is smooth.

Bravo (B) Surface of restoration is slightly rough or pitted, can be refinished. 
(range of 13-70 years). All patients were free of any active periodontal disease. Poor oral hygiene and evidence of heavy occlusion and/or tooth wear were considered as causes for exclusion from the study. All cavities were prepared and restorations were placed by the same operator in 42 maxillary teeth (23 anterior, 16 premolar, 3 molar) and 50 mandibular teeth (23 anterior, 18 premolar, 9 molar). Each patient received approximately three restorations. Operative procedures were generally performed without local anesthesia. Carious lesions were removed with a round bur (ISO 500104001 175012 ) or spoon excavator, and the margins of the cavity were finished using ultrafine grain diamond burs (ISO 806313289504 012) with water spray. Cavity preparation was limited to the removal of caries, and the exact cavity form and size were obtained after caries removal. The incisal or occlusal margins of the cavities were located in the cervical region and the cervical margins at the cementoenamel junction. The restorations were placed according to manufacturer's instructions as outlined in the following precedure. Isolation was achieved with cotton wool rolls and saliva ejector. After drying the cavity, one coat of PSA Prime/Adhesive (DeTrey/ Dentsply, Konstanz, Germany) was applied for 30 seconds, gently air-dried and light-cured for $10 \mathrm{sec}-$ onds. Then, a second coat was applied, immediately air-dried, and again light-cured for 10 seconds. Color matching was done with a Vita shade guide (Vita Zahnfabrik, Bad Sackingen,Germany), and the material - dispensed in compules - was injected into the cavity and light-cured for 40 seconds. The intensity of the curing light (XL3000, 3M Dental Products, St. Paul, MN, USA) was measured before and after application, and the light output was never below 450 $\mathrm{mW} / \mathrm{cm}^{2}$. Following the removal of excess material with fine diamond burs and strips, the restorations were finished and polished with Sof-Lex abrasive disks (3M Dental Products, St. Paul, MN, USA).

The restorations were evaluated by two experienced, calibrated examiners according to the modified Ryge criteria ${ }^{29)}$ (Table 1). Inter- and intra-examiner agreement for the evaluation criteria was $91 \%$. At baseline, first, second, and third year recall visits, color match, marginal discoloration, wear or loss of anatomical form, caries, marginal adaptation, and surface texture were evaluated.

According to the modified Ryge criteria ${ }^{29)}$, Alpha(A) rating represents a clinically ideal situation and Bravo(B) rating indicates a clinically acceptable situation. Charlie $(\mathrm{C})$ rating represents an unacceptable situation where the restoration requires replacement. Delta(D) rating indicates a situation where the restoration is missing, mobile or fractured and has to be replaced as the restoration is clinically unacceptable. Evaluation data obtained were statistically analyzed using Friedman test for the compari- son of years followed by Wilcoxon matched pairs test (with Bonferroni correction for multiple comparisons).

\section{RESULTS}

After one year, all patients attended their recall appointments. At second year recall visit, two patients (three restorations) dropped out, and at the third year recall visit one patient (two restorations) dropped out (Table 2). Recall rates for patients at the second and third years were $92.9 \%$ and $89.3 \%$ respectively.

After one year, two of the 92 Class $\mathrm{V}$ restorations were completely lost and one restoration had Charlie $(\mathrm{C})$ rating for anatomical form and marginal adaptation and had to be replaced. Retention rate after one year was $96.7 \%$. After two years, three restorations were completely lost and the retention rate was $93.5 \%$. After three years, one restoration was lost due to crown treatment and the retention rate was $92.4 \%$ (Table 2).

Direct clinical evaluation results at baseline, first, second, and third year recall visits are shown in Table 3. At first year recall visit, one of the restorations was clinically unacceptaple in regard to loss of anatomical form and marginal adaptation and had to be replaced. On the other hand, none of the restorations was clinically unacceptable in regard to color match, marginal discoloration, wear or loss of anatomical form, caries, marginal adaptation, and surface texture after two and three years. However, color change after three years was statistically significant $(p=0.013)$ with a substantial shift from clinically ideal color match (Alpha) to clinically acceptable color match (Bravo). Nonetheless, no replacements were required. In addition, there was statistically significant color change among all the evaluation periods, except between second and third year results.

Marginal discoloration was statistically significant $(\mathrm{p}<0.001)$ after three years and among all the evaluation periods except between second and third year results. However, the discoloration was clinically acceptable (Bravo) and did not require any restoration to be replaced (Table 3 ).

Statistical analysis showed no significant differ-

Table 2 History of the Restorations between Baseline and Three Years

\begin{tabular}{cccc}
\hline & $\begin{array}{c}\text { Missing (due to } \\
\text { patient drop-out) }\end{array}$ & Evaluated & $\begin{array}{c}\text { Lost since last } \\
\text { evaluation }\end{array}$ \\
\hline Baseline & - & 92 & - \\
1 year & - & 92 & 3 (replaced) \\
2 year & 3 & 86 & 3 (replaced) \\
3 year & 2 & 81 & 1 \\
\hline
\end{tabular}


Table 3 Results of Clinical Evaluation of Dyract Restorations (Observation are in per cent). A: Alfa, B: Bravo, C: Charlie, D: Delta

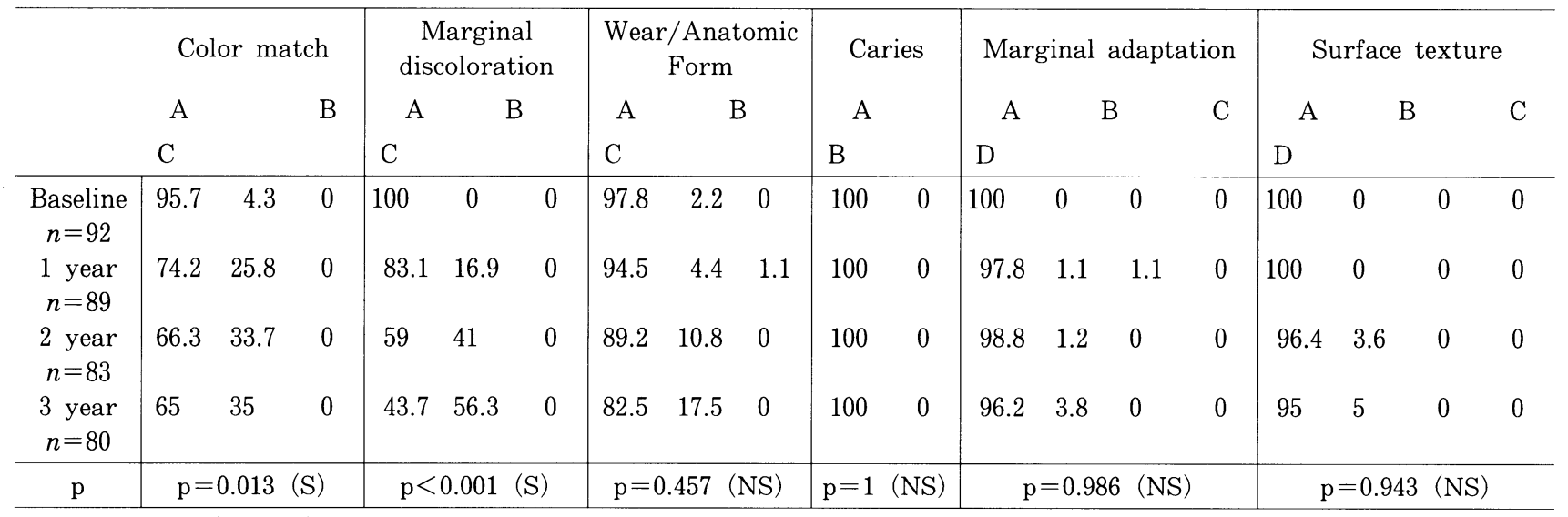

$\mathrm{S}=$ significant $(\mathrm{p}<0.05)$

$\mathrm{NS}=$ not significant

ences in marginal adaptation, wear or loss of anatomical form, and surface texture between baseline and three-year results. No secondary caries was detected during the three-year period. Moreover, at baseline, first, second and third year recall visits, none of the patients reported sensitivity.

\section{DISCUSSION}

At first year recall visit, the retention rate of Class $\mathrm{V}$ carious restorations was found to be $96.7 \%$, supporting the results of van Dijken ${ }^{30)}$ and Tyas ${ }^{11)}$ - reported to be $97.6 \%$ and $97 \%$ respectively. After two years, the retention rate of Dyract in Class $\mathrm{V}$ carious $^{24)}$ and abrasion lesions ${ }^{23)}$ have been reported to be $100 \%$. In another study conducted on Class V carious, erosion/noncarious lesions and the replacement of deficient restorations, the two-year retention rate was reported to be $91 \%{ }^{26)}$. In line with these studies, a retention rate of $93.5 \%$ was obtained at the end of second year in the present study. At the third year recall visit, the retention rate of Class $\mathrm{V}$ carious restorations was found to be $92.4 \%$ and in agreement with that of other reports at $>95 \%{ }^{12)}$ and $93.7 \%{ }^{31)}$.

At all observation periods in the present study, the retention rate was found to be relatively high which could be attributed to the adhesion mechanism of PSA Prime/Adhesive to dentin and enamel. Adhesion ability depends on the ionic bonding between carboxyl and phosphate groups, and the acetone component improves this ability by wetting the tooth surface $^{9,11,13-16,32)}$. Apart from adhesion ability, modulus of elasticity is also another factor that contributes to retention rate. It is reported that the elastic modulus of Dyract is higher than microfilled resin composites, but lower than that of hybrid resin composites $^{4,73-35)}$. Materials used in cervical restorations have a lower modulus of elasticity. When sub- jected to a masticatory load, they tend to bend more like tooth structure and may flex and be retained $^{26,36,37)}$. Further, in Class $\mathrm{V}$ carious cavities, a more retentive cavity form with undercuts is obtained since the surface area of the cavity is increased with the removal of caries. Then, with consequent increase in material volume, occlusal stresses may be better absorbed by the material or distributed to the cavity walls, thus making the material more resistant. When comparing the retention rate of Dyract with that of a composite resin and two resin-modified resin glass ionomers in Class $\mathrm{V}$ lesions, Folwaczny et $a .^{31)}$ found no statistically significant differences after three years.

There was a statistically significant difference in color match after three years $(p=0.013)$. The increase in color change from baseline to first, seocnd, and third year recall visits was statistically significant $(p<0.001)$. At baseline, Alpha rating of ideal color match was $95.7 \%$, and Bravo rating of clinically acceptable color match was $4.3 \%$. After three years, Alpha rating of ideal color match was $65 \%$. On the other hand, clinically acceptable color match rating increased by $30.7 \%$ with respect to baseline to reach $35 \%$. These findings showed a remarkable change in color match and reduced color stability at the end of three-year period. However, color change was more pronounced in the first year of the study. In the following two years, color change was less pronounced. In particular during the third year, there was barely any color change in restorations. Nevertheless, the color change observed in restorations was within the clinically acceptable color match range. These results were consistent with those of Di Lenerda et $a l .{ }^{38)}$ and Folwaczny et $a l .^{31)}$, whereby Alpha rating of ideal color match was found to be $77 \%$ after three years and $63.3 \%$ after four years respectively. Van Dijken ${ }^{39)}$ reported that due to the 
high hydrophilic monomer content of hybrid materials, there was a high water sorption rate which led to apparent color change. Cattani-Lorente et al $^{40)}$ further reported that the water absorption of Dyract continued for at least three months. As a result, water absorbed during the days and weeks after photopolymerization initiates an acid-base reaction and the setting continues ${ }^{9-11,27)}$. These factors might therefore explain the color change in this study.

In contrast to our results, Tyas ${ }^{27)}$ observed a close color match to tooth - which was highly satisfactory throughout the three-year trial - in noncarious cervical restorations. As for Gladys et $a l{ }^{41)}$, they demonstrated that the color change of Dyract occured in the first six months and was less pronounced in the following 12 months of their study. Color change was observed to range from "excellent color match" to "slight color mismatch" by the end of the first 12 months. Compared with their observations, the color change in the present study ranged from "clinically ideal color match (Alpha)" to "clinically acceptable color match (Bravo)", and the color change was more pronounced after one year. However, note that carious lesions were selected for this study - a parameter different from the studies of Tyas ${ }^{27)}$ and Gladys et al. ${ }^{41}$. Therefore, the cavities in the present study might be deeper than noncarious lesions. Further, since the volume of restorations increased, it might point to a higher rate of water sorption, thus leading to a more pronounced color change. Contrary to our first year results, Roeters et $a l^{42)}$ observed an improvement in color match for Dyract from "clinically acceptable color match (Bravo)" to "ideal color match (Alpha)" in primary Class I and Class II restorations. However, after three years, they also reported a color change from "ideal color match (Alpha)" to "clinically acceptable color match (Bravo)". Though their color change was more pronounced, their observations were basically in accordance with our three-year results. Difference in the first year results might be due to the different cavity types selected in the two studies. In some previous studies comparing Dyract with composites $^{31,43)}$, it was reported that the compomer showed the limitation of color match in Class $\mathrm{V}$ lesions, while composites exhibited better esthetic results. On the other hand, Folwaczny et $a l^{31)}$ obtained the poorest color match results in a three-year study with resin-modified glass ionomers, when compared to Dyract and a composite resin. However, Compoglass, also a compomer, has been shown to demonstrate a good color match with tooth structure as Fuji II LC - a resin-modified glass ionomer - did in cervical erosion/abfraction lesions after two years $^{44)}$.

After three years, marginal discoloration was seen in $56.3 \%$ of the restorations and was statistically significant. However, the discoloration was minimal, superficial, and not located on any specific point on the enamel surrounding the restoration. Furthermore, it could be polished off, indicating that it did not progress toward the pulp (Bravo rating). Therefore, although marginal discoloration was detected in a relatively high percentage of cases, they were all clinically acceptable. Staining of the adhesive or the penetration of stain between excessive adhesive and uncut enamel margin of cavity could have caused discoloration at the enamel level. It has been reported that the bond strength of self-etching primer is higher in cut enamel than in uncut (intact) enamel ${ }^{45)}$. On the other hand, the manufacturer of PSA Prime recommends the material to be applied alone without acid etching the enamel as the bond strength should be adequate ${ }^{9)}$. Dyract is basically a composite material ${ }^{27)}$. Thus, polymerization shrinkage may be one reason for marginal discoloration. Miyazaki et $a l{ }^{46)}$ reported the rate of polymerization shrinkage of Dyract to be $2.7 \%$. Therefore, it was suggested that polymerization shrinkage could be compensated for by increasing the bonding strength to tooth structure ${ }^{47}$.

It is well established that the bonding of resin composite to enamel is markedly improved by acid etching the enamel in order to create retentive microporosites ${ }^{27)}$. Since Dyract is a composite-based material, bonding strength should be higher when used with enamel etching ${ }^{11,47,48}$. Indeed, it has been reported that bonding strength increased by three times when enamel was etched as compared to unetched enamel ${ }^{48-50)}$. Microleakage studies also showed that when enamel was not etched, compomers showed poor marginal seal ${ }^{51,52)}$. Di Lenarda et $a l^{38)}$ observed in vivo marginal discoloration in $40 \%$ of the non-etched and $16.7 \%$ of the etched cervical restorations after 48 months with a statistically significant difference between these two groups. Tyas ${ }^{27)}$, without performing acid etching in enamel, also found some degree of rather severe marginal discoloration in 16 of the 36 noncarious cervical restorations, and reported that the amount of enamel marginal staining was of concern after three years. In this respect, the results of our study agreed with those of Tyas marginal discoloration was observed at the enamel level in $56.3 \%$ of the restorations at the third year recall visit. Tyas $^{27)}$ stated that although Dyract has now been superseded by Dyract AP with a finer filler particle, a cross-linking resin, and an optimized initiator system, the manufacturer should still consider specifying mandatory enamel etching. Following acid etching, Prati et $a l^{43)}$ found that Dyract exhibited, although not statistically significant, less marginal discoloration than a composite resin. Supporting their findings, Folwaczny et al. ${ }^{31)}$ showed that without acid etching, Dyract demonstrated more marginal discoloration than another resin composite. They also found that one resin-modified glass ionomer 
revealed marginal discoloration comparable to that of Dyract, while another resin-modified glass ionomer showed more marginal discoloration than Dyract. Marginal leakage, an indicator of bond deterioration like marginal discoloration, was found more intensively in the enamel margins of Dyract and a resinmodified glass ionomer than with a composite resin ${ }^{16)}$. Higher enamel bond strength - that may possibly lead to less marginal discoloration - was detected for six different compomers (Dyract, Dyract AP, F2000, F2000C, Compoglass, and Freedom) after phosphoric acid etching. Only Hytac, also a compomer, showed higher enamel bond strength without acid etching ${ }^{53)}$.

No statistically significant differences in wear/ anatomic form existed between baseline and threeyear results. After one year, only one restoration (1.1\%) had unacceptable anatomic form (Charlie rating) and had to be replaced. At the third year recall visit, $82.5 \%$ of the restorations were clinically ideal (Alpha rating) while only $17.5 \%$ were clinically acceptable (Bravo rating), meaning that $15.3 \%$ of the restorations had lost their anatomical form present at baseline. Wear was only limited to the restorative material and did not extend to the sound tooth structure.

At the third year recall visit, no secondary caries was detected. Statistical analysis showed no significant differences in marginal adaptation and surface texture between baseline and three-year results. After one year, only one restoration (1.1\%) had unaccaptable marginal adaptation (Charlie rating) and had to be replaced. At the end of three years, $96.3 \%$ of restorations had clinically ideal marginal adaptation (Alpha rating) and only $3.8 \%$ of the restorations had a crevice (Bravo rating). But for restorations with a crevice, dentin was not exposed and was thus rated as a clinically acceptable situation. After three years, in regard to surface texture, 5\% of the restorations were slightly pitted and had rough surfaces (Bravo rating) which could be restored by re-polishing.

\section{CONCLUSIONS}

1) After three years, seven of the 92 Class $V$ restorations were lost and retention rate was $92.4 \%$.

2) After three years, color change and marginal discoloration were statistically significant $(p<0.001)$. Nonetheless, all affected restorations were of Bravo rating and did not require any replacement.

3 ) After three years, Dyract exhibited good clinical success rate but significant color change and marginal discoloration in Class $\mathrm{V}$ restorations.

4) At baseline, first, second, and third year recall visits, none of the patients reported postoperative sensitivity.

\section{REFERENCES}

1) Croll TP. Glass ionomer for infants, children, and adolescents. J Am Dent Assoc 1990; 120: 65-68.

2) Croll TP. Glass ionomers and esthetic dentistry: What the new properties mean to dentistry. J Am Dent Assoc 1992; 123: 51-54.

3) Hammesfahr PD. Developments in resionomer systems. In: Glass Ionomers: The next generation, Hunt PR, ed. Proceeding of the $2^{\text {nd }}$ International Symposium on Glass Ionomers, Pennsylvania: International Symposia in Dentistry, PC, 1994, pp.47-56.

4) Sidhu SK, Watson TF. Resin-modified glass ionomer materials. A status report for the American Journal of Dentistry. Am J Dent 1995; 8: 59-67.

5) Hickel R, Dasch W, Janda R, Tyas M, Anusavice $K$. New direct restorative materials. Int Dent J 1998; 48: 3-16.

6) Burgess J, Norling B, Summit J. Resin ionomer restorative materials: The new generation. J Esthet Dent 1994; 6: 207-215.

7) McLean JW, Nicholson JW, Wilson AD. Proposed nomenclature for glass-ionomer dental cements and related materials. Quintessence Int 1994; 25: 587-589.

8) Gladys S, Van Meerbeek B, Braem M, Lambrechts P, Vanherle G. Comparative physico-mechanical characterization of new hybrid restorative materials with conventional glass-ionomer and composite restorative materials. J Dent Res 1997; 76: 883-894.

9) Dentsply DeTrey-DeDent (1994), Dyract product information Version III GB $7 / 94$.

10) Berg JH. The continuum of restorative materials in pediatric dentistry - A review for the clinician. Pediatr Dent 1998; 20: 93-100.

11) Tyas MJ. Clinical evaluation of a polyacid-modified resin composite (compomer). Oper Dent 1998; 23: 77-80.

12) Barkmeier WW, Hammesfahr PD, Latta MA. Bond strength of composite to enamel and dentin using Prime \& Bond 2.1. Oper Dent 1999; 24: 51-56.

13) Yap AUJ, Lim CC, Neo JCL. Marginal sealing ability of three cervical restorative systems. Quintessence Int 1995; 26: 817-820.

14) Abate PF, Bertacchini SM, Polack MA, Macchi RL. Adhesion of a compomer to dental structures. Quintessence Int 1997; 28: 509-512.

15) Toledano $M$, Osorio $\mathrm{E}$, Osorio $R$, Garcia-Godoy $F$. Microleakage of Class $\mathrm{V}$ resin-modified glass ionomer and compomer restorations. J Prosthet Dent 1999; 81: 610-615.

16) Çehreli ZC, Altay N. Three-year clinical evaluation of a polyacid-modified resin composite in minimally invasive occlusal cavities. J Dent 2000; 28: 117-122.

17) Friedl KH, Schmalz G, Hiller KA, Shams M. Resinmodified glass ionomer cements: Fluoride release and influence on streptococcus mutans growth. Euro J Oral Sci 1997; 105: 81-85.

18) Forsten L. Fluoride release and uptake by glassionomers and related materials and its clinical effect. Biomaterials 1998; 19: 503-508.

19) Shaw AJ, Carrick T, McCabe JF. Fluoride release 
from glass-ionomer and compomer restorative materials: 6-month data. J Dent 1998; 26: 355-359.

20) Itota $T$, Okamoto $M$, Sato $K$, Nakabo $S$, Nagamine $M$, Torii $\mathrm{Y}$, Inoue $\mathrm{K}$. Release and recharge of flouride by restorative materials. Dent Mater J 1999; 18: 347-353.

21) Marks LAM, Verbeeck RH. Water sensitivity of the fluoride release of modified glass ionomers. J Dent Res 1998; 77: 939 (IADR Abstract 2431).

22) Gomec Y, Dorter C, Ersev H, Efes Guray B, Yıldız E. Effects of dietary acids on microhardness of various tooth-colored restoratives. Dent Mater J 2004; 23: 429435.

23) Abdalla AI, Alhadainy HA. Clinical evaluation of hybrid ionomer restoratives in Class $\mathrm{V}$ abrasion lesions: Two-year results. Quintessence Int 1997; 28: 255-258.

24) Abdalla AI, Alhadainy HA, Garcia-Godoy F. Clinical evaluation of glass ionomers and compomers in Class $\mathrm{V}$ carious lesions. Am J Dent 1997; 10: 18-20.

25) Cadenero $M$, Di Lenarda R, Cernaz A. A 42-month clinical evaluation of Dyract glass ionomer. J Dent Res 1998; 77: 953 (IADR Abstract 2572).

26) Folwaczny $\mathrm{M}$, Loher $\mathrm{C}$, Mehl A, Kunzelmann $\mathrm{KH}$, Hinkel R. Tooth-colored filling materials for the restoration of cervical lesions: A 24-month follow-up study. Oper Dent 2000; 25: 251-258.

27) Tyas MJ. Three-year clinical evaluation of a polyacidmodified resin composite (Dyract). Oper Dent 2000; 25: 152-154.

28) Wicht MJ, Fritz UB, Noack MJ. A one-year follow-up of Dyract restorations. J Dent Res 1997; 76: 165 (IADR Abstract 1210).

29) Ryge G. Clinical criteria. Int Dent J 1980; 30: 347-358.

30) Van Dijken JWV. Clinical evaluation of Dyract, Vitremer, Permagen and Syntac. J Dent Res 1995; 74: 433 (IADR Abstract 259).

31) Folwaczny $M$, Loher $\mathrm{C}$, Mehl A, Kunzelmann $\mathrm{KH}$, Hickel R. Class V lesions restored with four different tooth-colored materials: 3 -year results. Clin Oral Invest 2001; 5: 31-39.

32) Ferrari M, Vichi A, Mannocci F, Davidson CL. Sealing ability of two "compomers" applied with and without phosphoric acid treatment for Class $\mathrm{V}$ restorations in vivo. J Prosthet Dent 1998; 79: 131-135.

33) Braem MJA, Lambrechts $\mathrm{P}$, Gladys $\mathrm{S}$, Vanherle G. In vitro fatigue behavior of restorative composites and glass ionomers. Dent Mater 1995; 11: 137-141.

34) Irie M, Nakai H. Flexural properties and swelling after storage in water of polyacid-modified composite resins (compomers). Dent Mater J 1998; 17: 77-82.

35) Uno S, Tanaka T, Inoue $S$, Sano $H$. The influence of configuration factors on cavity adaptation in compomer restorations. Dent Mater J 1999; 18: 19-31.

36) Heymann HO, Sturdevant JR, Bayne SC, Wilder AD, Sluder TB, Brunson WD. Examining tooth flexure effect on cervical restorations: A two-year clinical study. J Am Dent Assoc 1991; 122: 41-47.

37) Matis BA, Cochran M, Carlson T. Longevity of glassionomer restorative materials: Results of a 10-year evaluation. Quintessence Int 1996; 27: 373-382.
38) Di Lenarda R, Cadenaro M, De Stefano Dorigo E. Cervical compomer restorations: The role of cavity etching in a 48-month clinical evaluation. Oper Dent 2000; 25: 382-387.

39) Van Dijken JWV. Three-year clinical evaluation of a compomer, a resin-modified glass ionomer and a resin composite in Class III restorations. Am J Dent 1996; 9: 195-198.

40) Cattani-Lorente MA, Dupuis V, Moya F, Payan J, Meyer JM. Comparative study of the physical properties of a polyacid-modified composite resin and a resinmodified glass ionomer cement. Dental Materials 1999; 15: 21-32.

41) Gladys S, Van Meerbeek B, Lambrechts P, Vanherle G. Evaluation of esthetic parameters of resin-modified glass-ionomer materials and a polyacid-modified resin composite in Class $\mathrm{V}$ cervical lesions. Quintessence Int 1999; 30: 607-614.

42) Roeters JJM, Frankenmolen F, Burgersdijk RCW, Peters TCRB. Clinical evaluation of Dyract in primary molars: 3-year results. Am J Dent 1998; 11: 143-148.

43) Prati C, Chersoni S, Cretti L, Montanari G. Retention and marginal adaptation of a compomer placed in nonstress bearing areas used with the total-etch technique: A 3-year retrospective study. Clin Oral Invest 1998; 2: 168-173.

44) Brackett WW, Browning WD, Ross JA, Brackett MG. Two-year clinical performance of a polyacid-modified resin composite and a resin-modified glass-ionomer restorative material. Oper Dent 2001; 26: 12-16.

45) Kanemura N, Sano H, Tagami J. Tensile bond strength and SEM evaluation of ground and intact enamel surfaces. J Dent 1999; 27: 523-530.

46) Miyazaki M, Fukuishi K, Onose $H$. Influence of light irradiation on the volumetric change of polyacidmodified resin composites. J Dent 1999; 27: 149-153.

47) Cortes O, Garcia-Godoy F, Boj JR. Bond strength of resin-reinforced glass ionomer cements after enamel etching. Am J Dent 1993; 6: 299-301.

48) Kusunoki M, Itoh $K$, Hisamitsu $H$, Wakumoto S. Marginal adaptation of commercial compomers in dentin cavity. Dent Mater J 1998; 17: 321-327.

49) Desai M, Tyas MJ. Adhesion to enamel of light-cured polyacid dental materials. Aust Dent J 1996; 41: 393397.

50) Cortes O, Garcia C, Perez L, Bravo LA. A comparison of the bond strength to enamel and dentin of two compomers: An in vitro study. ASDC J Dent Child 1998; 65: 29-31.

51) Brackett WW, Gunnin TD, Gilpatrick RO, Browning WD. Microleakage of Class $\mathrm{V}$ compomer and lightcured glass ionomer restorations. J Prosthet Dent 1998; 79: 261-263.

52) Owens BM, Halter TK, Brown DM. Microleakage of tooth-colored restorations with a beveled gingival margin. Quintessence Int 1998; 29: 356-361.

53) Tate WH, You C, Powers JM. Bond strength of compomers to human enamel. Oper Dent 2000; 25: 283291. 